\title{
EDITORIAL
}

\section{Is the literature inconclusive about the harm from HES? No}

\author{
Christian J. Wiedermann ${ }^{1 *}$, Rinaldo Bellomo ${ }^{2}$ and Anders Perner ${ }^{3}$
}

(c) 2016 Springer-Verlag Berlin Heidelberg and ESICM

\section{Introduction}

Colloid solutions may be more effective than crystalloid solutions in expanding the intravascular space, which may result in improved hemodynamics and reduced tissue edema. Whether this is clinically important is unknown. Despite lack of evidence of overall benefit in terms of clinical or patient-important outcome measures, hydroxyethyl starch (HES), an artificial colloid solution, has been used in a variety of clinical settings to treat hypovolemia including during surgery, after trauma and burns, in sepsis, and in critically ill patients. As we will outline below, HES has clear side effects based on well-described pathophysiologic pathways resulting in worse outcome in critically ill patients.

\section{Acute kidney injury}

Hydroxyethyl starch has been shown to increase the risk of acute kidney injury (AKI) and need for renal replacement therapy (RRT) as compared to other fluid solutions in different clinical settings [1]. The effects are independent of molecular weight, molar substitution, C2/C6 ratio, and dose of HES. Increased use of RRT with HES vs other fluids has been shown in surgical and non-surgical intensive care patients, and in patients with sepsis [2-5]. Because most of these data are from trials done in ICU, the effects of HES on kidney function in the intraoperative period have yet to be settled.

The nephrotoxic pathway of HES is likely secondary to renal tissue uptake and storage because HES cannot be degraded once it leaves the circulation $[6,7]$. Moreover, HES is by no means confined to the intravascular

\footnotetext{
*Correspondence: christian.wiedermann@asbz.it

${ }^{1}$ Department of Internal Medicine, Central Hospital of Bolzano,

Lorenz-Böhler-Street 5, 39100 Bolzano, BZ, Italy

Full author information is available at the end of the article
}

Contrasting viewpoints can be found at doi:10.1007/s00134-016-4278-7 and doi:10.1007/s00134-016-4329-0. compartment. Up to $50 \%$ of administered volumes cannot be accounted for in blood or urine at $24 \mathrm{~h}$ after infusion meaning that this amount resides in other compartments where it cannot be degraded [6]. In the kidney, HES may induce osmotic nephrotic lesions [7] and tubular obstruction by hyperviscous urine and inflammation [8]. HES-related inflammation has also been observed in other organs months after intravenous infusion, including liver and bone marrow [7].

\section{Bleeding}

In general, the data on HES and clinical bleeding are less robust than those on AKI. However, recent trials have shown increased risk of bleeding with the use of HES as compared to crystalloid solutions in patients with sepsis [9] and those undergoing major surgery $[10,11]$. In a meta-analysis of patients undergoing cardiac surgery, HES solutions were associated with increased postoperative blood loss and rates of reoperation for bleeding compared to albumin [12]. Other meta-analyses including data on HES and bleeding have been published by authors with ties to the industry [13]. Their results have favored HES, but the authors have been criticized for biased inclusion of control groups and data imputation. HES-induced bleeding is likely the result of direct effects on hemostasis through impaired fibrinogen/fibrin polymerization resulting in weaker and smaller blood clots [14].

\section{Increased risk of death}

After inclusion of data from large high-quality trials [2, 15], the updated Cochrane meta-analysis of colloids vs crystalloids in critically ill patients showed increased mortality with HES [16]. Additional meta-analyses confirmed this finding using different methodologies and in different settings underlining the robustness of the data $[3,17]$. 


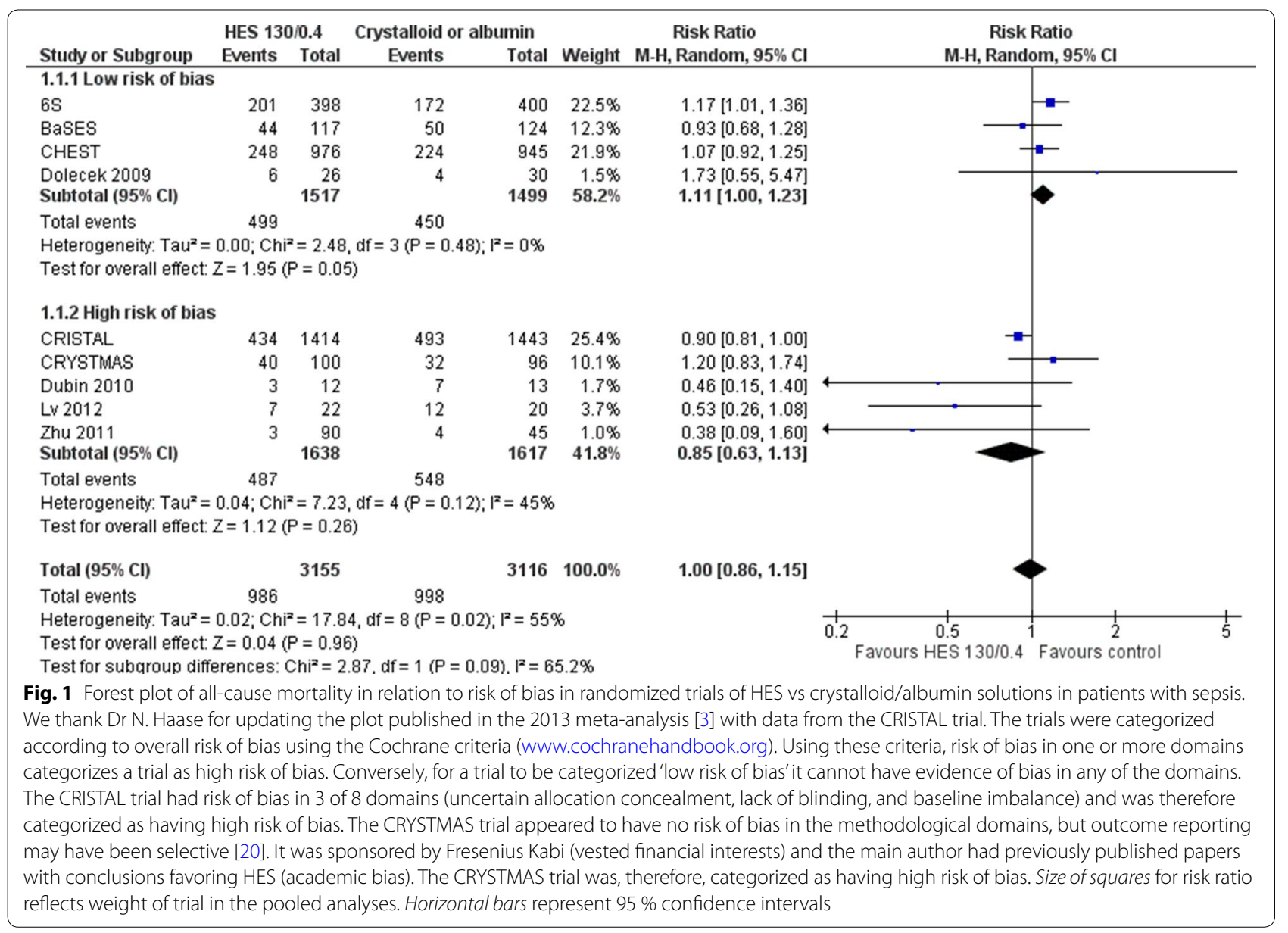

\section{Misleading trial results}

Risk of bias is very important when interpreting trials of HES. When adding mortality data from the subgroup of patients with sepsis in the CRISTAL trial (even though not strictly randomizing patients to HES vs crystalloid [18]) to the cumulative evidence of HES vs crystalloid/ albumin in sepsis [3], there was heterogeneity in the results for mortality based on risk of bias; the high risk of bias trials showed the opposite of the low risk of bias trials (for details, see Fig. 1). It is well established that risk of bias results in overestimation of the intervention effect on objective outcome measures in RCTs [19], and this appears also to be the case for the effect of HES vs crystalloid/albumin on mortality. The overall result of this metaanalysis (Fig. 1) is heavily affected by the high risk of bias trials, which also shows how misleading these analyses may be if proper risk of bias adjustments are not made.

\section{Conclusions}

The evidence from high-quality meta-analyses shows that fluid therapy with HES vs crystalloids increases the rate of AKI and mortality in critically ill patients. Thus, the European Medicines Agency (EMA) has made the legally binding decision (EMA/809470/2013) that HES cannot be used in these patients nor in those with sepsis or burn-related injury. Although currently data are insufficient to identify a difference in outcomes of perioperative fluid therapy in non-cardiac surgery, the use of HES also appears to be associated with increased risk of bleeding in patients with sepsis and those undergoing surgery as compared with the use of crystalloid or albumin solutions.

The literature about harm of HES is conclusive and the mechanisms of toxicity have been identified. The harmful effects of HES appear to be common to all HES classes and dose dependent. No safe dose of HES has been defined $[1,17]$. Since there are no data from trials with adequate methodology and power showing clinically important benefits from using HES in any clinical setting, the EMA has requested the marketing authorization holders of HEScontaining medicinal products to perform postauthorization safety studies. Results of these studies will determine if the use of HES will have to be further restricted. 


\section{Author details}

1 Department of Internal Medicine, Central Hospital of Bolzano, Lorenz-Böhler-Street 5, 39100 Bolzano, BZ, Italy. ${ }^{2}$ Department of Intensive Care, Austin Hospital, 145 Studley Road, Heidelberg VIC 3084, Australia. ${ }^{3}$ Department of Intensive Care, Copenhagen University Hospital, Rigshospitalet, 2100 Copenhagen, Denmark.

Received: 31 December 2015 Accepted: 15 February 2016 Published online: 23 March 2016

\section{References}

1. Mutter TC, Ruth CA, Dart AB (2013) Hydroxyethyl starch (HES) versus other fluid therapies: effects on kidney function. Cochrane Database Syst Rev 7:CD007594

2. Myburgh JA, Finfer S, Bellomo R et al (2012) Hydroxyethyl starch or saline for fluid resuscitation in intensive care. N Engl J Med 367:1901-1911

3. Haase N, Perner A, Hennings LI et al (2013) Hydroxyethyl starch 130/0.380.45 versus crystalloid or albumin in patients with sepsis: systematic review with meta-analysis and trial sequential analysis. BMJ 346:f839

4. Rochwerg B, Alhazzani W, Gibson A et al (2015) Fluid type and the use of renal replacement therapy in sepsis: a systematic review and network meta-analysis. Intensive Care Med 41:1561-1571. doi:10.1007/ s00134-015-3794-1

5. Wilkes MM, Navickis R (2014) Postoperative renal replacement therapy after hydroxyethyl starch infusion: a meta-analysis of randomised trials. Neth J Crit Care 18:4-9

6. Bellmann R, Feistritzer C, Wiedermann CJ (2012) Effect of molecular weight and substitution on tissue uptake of hydroxyethyl starch: a metaanalysis of clinical studies. Clin Pharmacokinet 51:225-236

7. Wiedermann CJ, Joannidis M (2014) Accumulation of hydroxyethyl starch in human and animal tissues: a systematic review. Intensive Care Med 40:160-170

8. Claus RA, Sossdorf M, Hartog C et al (2010) The effects of hydroxyethyl starch on cultured renal epithelial cells. Anesth Analg 110:300-301
9. Haase N, Wetterslev J, Winkel P, Perner A (2013) Bleeding and risk of death with hydroxyethyl starch in severe sepsis: post hoc analyses of a randomized clinical trial. Intensive Care Med 39:2126-2134

10. Rasmussen KC, Johansson PI, Højskov M et al (2014) Hydroxyethyl starch reduces coagulation competence and increases blood loss during major surgery: results from a randomized controlled trial. Ann Surg 259:249-254

11. Kancir AS, Johansen JK, Ekeloef NP et al (2015) The effect of $6 \%$ hydroxyethyl starch 130/0.4 on renal function, arterial blood pressure, and vasoactive hormones during radical prostatectomy: a randomized controlled trial. Anesth Analg 120:608-618

12. Navickis RJ, Haynes GR, Wilkes MM (2012) Effect of hydroxyethyl starch on bleeding after cardiopulmonary bypass: a meta-analysis of randomized trials. J Thorac Cardiovasc Surg 144:223-230

13. Jacob M, Fellahi JL, Chappell D et al (2014) The impact of hydroxyethyl starches in cardiac surgery: a meta-analysis. Crit Care 18:656

14. Hartog CS, Reuter D, Loesche W et al (2011) Influence of hydroxyethyl starch (HES) 130/0.4 on hemostasis as measured by viscoelastic device analysis: a systematic review. Intensive Care Med 37:1725-1737

15. Perner A, Haase N, Guttormsen AB et al (2012) Hydroxyethyl starch 130/0.42 versus Ringer's acetate in severe sepsis. N Engl J Med 367:124-134

16. Perel P, Roberts I, Ker K (2013) Colloids versus crystalloids for fluid resuscitation in critically ill patients. Cochrane Database Syst Rev 2:CD000567

17. Zarychanski R, Abou-Setta AM, Turgeon AF et al (2013) Association of hydroxyethyl starch administration with mortality and acute kidney injury in critically ill patients requiring volume resuscitation: a systematic review and meta-analysis. JAMA 309:678-688

18. Annane D, Siami S, Jaber S et al (2013) Effects of fluid resuscitation with colloids vs crystalloids on mortality in critically ill patients presenting with hypovolemic shock: the CRISTAL randomized trial. JAMA 310:1809-1817

19. Savović J, Jones HE, Altman DG et al (2012) Influence of reported study design characteristics on intervention effect estimates from randomized, controlled trials. Ann Intern Med 157:429-438

20. Hartog CS, Reinhart K (2012) CRYSTMAS study adds to concerns about renal safety and increased mortality in sepsis patients. Crit Care 16:454 